\title{
A revista Cais entre o protagonismo e o assistencialismo: Uma análise discursiva crítica
}

Initiative vs. Charity: A Critical Discourse Analysis of Cais Magazine

La revue Cais entre le protagonisme et l'assistanat : une analyse discursive critique

\section{Viviane de Melo Resende}

\section{OpenEdition}

\section{Journals}

\section{Edição electrónica}

URL: http://journals.openedition.org/rccs/1490

DOI: $10.4000 /$ rccs. 1490

ISSN: 2182-7435

\section{Editora}

Centro de Estudos Sociais da Universidade de Coimbra

Edição impressa

Data de publição: 1 Setembro 2011

Paginação: 21-40

ISSN: 0254-1106

\section{Refêrencia eletrónica}

Viviane de Melo Resende, «A revista Cais entre o protagonismo e o assistencialismo: Uma análise discursiva crítica », Revista Crítica de Ciências Sociais [Online], 94 | 2011, colocado online no dia 01 outubro 2012, criado a 02 maio 2019. URL : http://journals.openedition.org/rccs/1490 ; DOI : $10.4000 /$ rccs. 1490

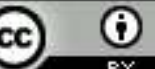




\section{VIVIANE DE MELO RESENDE}

\section{A revista Cais entre o protagonismo e o assistencialismo: Uma análise discursiva crítica}

Como parte dos resultados de um projeto integrado cujo escopo é investigar, por meio de análises discursivas, as práticas envolvidas na produção e na distribuição de cinco publicações em língua portuguesa voltadas para a situação de rua, este artigo focaliza, com base na Análise de Discurso Crítica, a revista Cais, publicada em Lisboa. Configurando-se como jornal de rua, a revista é vendida na rua e por pessoas em situação de rua ou de risco, para as quais revertem $70 \%$ da venda de cada exemplar. Mais que um meio de comunicação e difusão de problemas sociais, acredita-se que esse tipo de imprensa proporciona a configuração de posições e relações diferentes, podendo por isso alterar a experiência da exclusão. Neste artigo, tomando como dados excertos de uma entrevista com o seu editor, exploro em que medida se dá a participação de pessoas em situação de rua na produção da revista Cais e na representação desta mesma situação.

Palavras-chave: análise do discurso; Brasil; exclusão social; imprensa de rua; meios de comunicação social; Portugal; sem-abrigo.

\section{Introdução}

Neste artigo, apresento resultados parciais de trabalho associado ao projeto integrado "Publicações em língua portuguesa sobre população em situação de rua: análise de discurso crítica”, cujo objetivo é investigar as cinco publicações localizadas, em língua portuguesa, voltadas para a abordagem específica da população em situação de rua. São elas: a revista Ocas e o jornal O Trecheiro, de São Paulo; o jornal Boca de Rua, de Porto Alegre; o jornal Aurora da Rua, de Salvador; e a revista Cais, de Lisboa. ${ }^{1}$

\footnotetext{
${ }^{1}$ Integram o projeto, sob minha orientação, María del Pilar Tobar Acosta, que já investigou o jornal O Trecheiro e agora estuda a revista Ocas; Andreia Alves dos Santos, que se dedica ao jornal Boca de Rua; Gersiney Pablo Santos, que pesquisa o jornal Aurora da Rua; e Diego da Silva Hilarino, que analisa, com o referencial da Gramática do Design Visual, imagens publicadas em O Trecheiro.
} 
O projeto integrado propõe um estudo qualitativo no qual a análise de dados baseia-se em métodos desenvolvidos na Análise de Discurso Crítica (ADC). A geração/coleta de dados inclui entrevistas focalizadas e dados de natureza documental (Resende, 2009). ${ }^{2}$ Assim, por um lado, fizemos a coleta de textos de edições recentes dos cinco periódicos, para a composição de um corpus documental. Por outro lado, também trabalhamos com entrevistas com os/as editores/as e colaboradores/as das cinco publicações. ${ }^{3}$ Essa triangulação metodológica para a coleta e a geração de dados justifica-se pela ontologia do funcionamento da linguagem na sociedade em ADC, e a necessária consistência epistemológica e metodológica, como buscarei esclarecer na primeira seção. Neste artigo, o foco é a revista Cais. Aqui me limito a analisar, com ferramentas da ADC, recortes da entrevista realizada com o editor da revista, em julho de $2011 .{ }^{4}$

Além desta introdução e das considerações finais, este artigo está dividido em quatro seções. Na primeira, discuto a Análise de Discurso Crítica, conforme o modelo teórico escolhido para o estudo. $\mathrm{Na}$ segunda seção, abordo a imprensa de rua em geral e a revista Cais em particular. Em seguida, na terceira seção, contextualizo o trabalho de campo realizado em Lisboa. ${ }^{5} \mathrm{Na}$ quarta seção, apresento a análise discursiva crítica dos dados, apropriando-me de categorias analíticas desenvolvidas nos estudos críticos do discurso, como a transitividade e a pressuposição. ${ }^{6} \mathrm{O}$ objetivo específico da análise empreendida é investigar a construção discursiva do "vendedor" na entrevista com o editor, a fim de verificar o grau de participação do grupo classificado como 'vendedores/as' na produção da revista, na representação

\footnotetext{
${ }^{2}$ Importa ressaltar que o projeto foi aprovado pelo Comitê de Ética do Instituto de Ciências Humanas da Universidade de Brasília em julho de 2010.

${ }^{3}$ O projeto "Publicações em língua portuguesa sobre população em situação de rua: análise de discurso crítica" recebeu apoio da Fundação de Apoio à Pesquisa do Distrito Federal (FAP-DF), Edital 3/2010, Processo 2010/00090-1.

${ }^{4}$ Opto pela tradução 'Análise de Discurso Crítica' para 'Critical Discourse Analysis', em lugar de 'Análise Crítica do Discurso'. Justifico a minha escolha pela tradição histórica dos estudos discursivos no Brasil, consolidados com o rótulo 'análise de discurso'. Tome-se como mais um argumento - este diretamente ligado à tradução do termo em si - o texto de van Dijk (1996), em que ambas as formas aparecem: "Critical Discourse Analysis" (p. 84) e "critical analysis of discourses" (p. 102). Parece-me coerente traduzir a primeira por 'Análise de Discurso Crítica' e a segunda por 'análise crítica de discursos'. Para uma reflexão mais detida sobre isso, ver Magalhães (2005).

${ }^{5}$ A realização do trabalho de campo em Lisboa foi possível graças ao apoio do Centro de Estudos Sociais da Universidade de Coimbra, no âmbito do Prêmio Jovens Investigadores 2011.

${ }^{6}$ Para Cunha e Souza (2007: 54), pela análise das seleções particulares de processos de transitividade em textos, podemos investigar as maneiras como se representam aspectos do mundo, já que essas escolhas representacionais "permitem analisar quem faz o quê, a quem e em que circunstâncias". Por meio da análise de recursos linguísticos ativadores de pressuposição, é possível verificar quais as proposições que são "tomadas pelo produtor do texto como já estabelecidas ou 'dadas'" (Fairclough, 2001: 155), o que pode apontar para o consenso ou a normalização.
} 
de seu editor. Por fim, levanto algumas considerações finais, procurando articular as análises apresentadas às teorias discutidas.

\section{Análise de Discurso Crítica: linhas gerais de um campo complexo}

Antes de tudo, precisamos de uma definição, mesmo que breve, de Análise de Discurso Crítica. Quando se fala em ADC, é preciso esclarecer a que versão se pretende referir: a $\mathrm{ADC}$ não é um corpo teórico homogêneo, ao contrário, é constituída por uma heterogeneidade de abordagens identificadas com o rótulo (Blommaert, 2005). Em Resende (2009), ressalto que, ainda que diversas em suas premissas teóricas e metodológicas, as versões de ADC guardam certas características em comum, o que garante coerência ao campo. Essas características comuns são, pelo menos, três: a interdisciplinaridade, o posicionamento crítico e a utilização de categorias linguísticas como ferramentas para a crítica social.

Todas as diferentes vertentes da ADC reconhecem que a transgressão dos limites disciplinares é um pressuposto básico para a análise de problemas sociais parcialmente discursivos, dada a relação interna entre linguagem e sociedade (Pardo Abril, 2007). Assim, cada uma das diferentes versões de ADC procura operacionalizar conceitos e categorias desenvolvidos em ciências sociais. Algumas abordagens constituem influentes corpos teóricos e metodológicos, com pesquisadores/as adeptos/as em Portugal, no Brasil e em toda a América Latina. É o caso das propostas de Norman Fairclough, Teun van Dijk, Theo van Leeuwen e Ruth Wodak, que estabelecem diferentes relações interdisciplinares em suas versões de ADC.

Mas quando se fala em ADC, há que considerar também os avanços realizados por pesquisadores/as latino-americanos/as. Esses/as pesquisadores/as não só têm contribuído para a difusão da ADC como teoria e método de investigação, mas também têm gerado abordagens próprias, questionando as abordagens já legitimadas e introduzindo avanços que não podem nem devem ser minimizados. ${ }^{7}$ Assim, importa aqui salientar o vínculo do projeto integrado de que este trabalho é parte à Red Latinoamericana de Análisis Crítico del Discurso de las personas sin techo y en extrema pobreza (REDLAD). ${ }^{8}$

\footnotetext{
7 Ver, por exemplo, Magalhães (2000), Meurer (2004), Pardo Abril (2008), Pardo (2008), Montecino (2010), Ramalho (2010) e Resende (2010).

${ }^{8}$ Reunindo recortes de pesquisas realizadas em países membros da rede, foram publicados trabalhos coletivos, como os livros El discurso sobre la pobreza en América Latina (Pardo, org., 2008) e Discurso, pobreza y exclusión en América Latina (Montecino, org., 2010). O esforço da rede tem contribuído também para a formulação de relações interdisciplinares em ADC, tanto em termos teóricos quanto metodológicos. A REDLAD é um exemplo produtivo da ampliação do potencial de analistas de discurso quando trabalham em rede. Acredito nas iniciativas coletivas - penso que a formação de redes de pesquisa congregando pesquisadores/as com interesses comuns amplifica a nossa capacidade de ação sobre os problemas que investigamos.
} 
Além da interdisciplinaridade, outra característica basilar das diversas propostas teórico-metodológicas em ADC é seu caráter posicionado. Em todas as suas vertentes, a ADC propõe abordagens críticas para a análise de textos, assumindo posição explícita em relação a problemas sociais de cunho discursivo e negando o mito da 'imparcialidade científica'. O objetivo, portanto, é desvelar discursos e ideologias que sustentem estruturas de dominação. De acordo com esse propósito, o conceito de ideologia mais adequado parece ser o de Thompson (1995), para quem ideologias são construções simbólicas a serviço de relações de poder, entendidas como dominação. O que interessa à $\mathrm{ADC}$ não é a noção abstrata de poder, mas o abuso de poder em contextos específicos (van Dijk, 2008).

$\mathrm{Na}$ versão de ADC de Fairclough, o foco é a relação entre discurso e mudança social, e uma questão crucial, quando se focaliza a mudança social, é a questão da relação entre estrutura e ação, ou entre sociedade e indivíduo. Sob influência do modelo teórico de constituição da sociedade desenvolvido no Realismo Crítico (RC), o foco em ADC não está na estrutura social ou na ação individual, mas na relação entre estrutura e ação, como modo de focalizar, simultaneamente, os constrangimentos e possibilidades oriundos da estrutura, que informam a ação, e os efeitos potenciais da ação reificadora ou transformadora de estruturas. De acordo com esse modelo, a sociedade provê as condições para a ação humana, mas só existe nas ações humanas, que sempre utilizam alguma forma preexistente de ordem social (Bhaskar, 1998). Essa assimetria temporal entre estrutura e ação implica que a sua relação não é de equivalentes, o que leva a uma entidade organizacional intermediária: a prática social. Prática social é, para Bhaskar, conceito intermediador entre as estruturas sociais abstratas e a ação social concreta.

O conceito de prática social possibilita um foco nas condições estruturais para a ação, na relação transformacional entre estrutura social e agência. Essa ontologia do RC pode ser aplicada à organização social da linguagem: no nível de abstração das estruturas sociais temos os sistemas semióticos; no nível de concretude da ação social temos os textos - materialização de nossas ações discursivas; e como entidades organizacionais intermediárias temos as ordens de discurso e os seus elementos constituintes - gêneros, discursos e estilos (Fairclough, 2003; como discutido a seguir). Essa abordagem nos permite focalizar, em termos discursivos, não os sistemas semióticos em si mesmos, nem a ação discursiva isolada, mas os tipos de relação que se estabelecem entre sistemas semióticos e produção textual em contextos específicos, ligados às práticas desempenhadas.

De acordo com Harvey (1992), toda prática social é composta de momentos articulados e irredutíveis a um. $\mathrm{Na}$ recontextualização para a 
ADC, os momentos constituintes de uma prática social são: semiose, atividade material, relações sociais e atores sociais, com as suas crenças, os seus valores, os seus desejos, e as ideologias que lhes podem estar subjacentes (Chouliaraki e Fairclough, 1999). Nessa perspectiva, o momento semiótico (de construção intersubjetiva de significados por meio de linguagens) é um dos momentos da prática social, ao lado de outros momentos que também devem ser contemplados em análises. O momento semiótico, que constitui outros elementos sociais, assim como é informado por eles, por sua vez também possui os seus momentos internos, teorizados em três dimensões: a ação discursiva, a representação discursiva e a identificação discursiva.

A ação discursiva diz respeito aos modos como, por meio das linguagens materializadas em textos, agimos sobre o mundo e sobre outras pessoas. Para isso, selecionamos diferentes 'tipos relativamente estáveis de enunciados', os gêneros do discurso (Bakhtin, 1992). A representação discursiva refere-se a modos relativamente estáveis de representar a experiência - um mesmo aspecto do mundo (por exemplo, a situação de rua) pode ser representado segundo diferentes discursos, que podem estar em relação de competição (por exemplo, o discurso assistencialista e o discurso do protagonismo). É nesse sentido que podemos identificar diferentes discursos políticos ou, por exemplo, o discurso neoliberal em sua oposição com os discursos "por uma outra globalização" (Santos, 2000). A identificação discursiva, por sua vez, diz respeito a modos de identificação por meio de textos, o que inclui identidades e alteridades.

A interdisciplinaridade e o posicionamento como características fundamentais às diferentes abordagens em ADC implicam uma terceira: em análises discursivas críticas, a utilidade de teorias e categorias linguísticas não é pressuposta; ao contrário, é emergente dos dados e dos objetivos da análise (Resende, 2009). A linguística, portanto, serve como instrumento para a crítica social, já que o propósito das análises é a crítica sustentada pela análise de textos. Assim, a seleção das categorias linguísticas utilizadas em estudos discursivos críticos deve ser justificada pela sua utilidade na análise da materialização discursiva de problemas sociais (Quiroz, 2008). Em ADC, a mera descrição de fenômenos linguísticos ou a exposição de conhecimento da metalinguagem desse campo, quando vazias de propósito crítico, são indesejáveis.

Essas três características apontadas como basilares em ADC mantêm estreita ligação entre si. Sendo a ADC "uma abordagem do uso da linguagem que objetiva explorar e expor os papéis do discurso na reprodução (ou resistência) das desigualdades sociais" (Richardson, 2007: 6; grifos no original), o seu interesse investigativo extrapola os fenômenos linguísticos. Esse escopo ampliado em que os processos de mudança discursiva são analisados tendo 
em vista os processos sociais resulta, por sua vez, na exigência da articulação com outras disciplinas, isto é, no pressuposto da interdisciplinaridade. E nas relações interdisciplinares estabelecidas, as categorias linguísticas mostram-se ferramentas úteis para a crítica social.

\section{A imprensa de rua e a revista Cais}

Já se tornou lugar-comum afirmar que o neoliberalismo reduziu o papel dos Estados nacionais, minando as conquistas do Estado de Bem-Estar Social - no que se refere tanto aos direitos contratuais de trabalhadores/as quanto aos direitos universais de cidadãos/ãs. A retirada do Estado do serviço social é denominada por Bourdieu (1998) como a 'demissão do Estado' e, de acordo com Buarque (2001: 241), "as organizações não governamentais surgiram em decorrência da falência do Estado no que diz respeito à ausência de respostas aos problemas surgidos em face dos novos valores éticos da sociedade".

Nesse quadro, há organizações que tentam suprir a lacuna deixada pelo Estado no que se refere à oferta de serviços, e há também organizações e movimentos sociais de papel reivindicatório que atuam como pressão sobre o Estado, exigindo-lhe a garantia de direitos assegurados e denunciando a sua violação. Esses movimentos de cunho protagonista são de extrema importância para a formação do ator social coletivo, capaz de agir na direção de um objetivo comum (Resende, 2008). Será esse o caso dos jornais de rua (street papers), que enunciam como seus objetivos gerar renda e abrir um canal de expressão para a população em situação de rua? Essas publicações e as organizações de que são parte promovem o protagonismo para a mudança social ou enquadram intervenções verticais? Como se situam na tensão entre os discursos do assistencialismo e do protagonismo? Um dos objetivos do estudo de que este artigo é recorte é compreender em que medida essas iniciativas constituem possibilidades de autorrepresentação para grupos sociais que são, em geral, representados negativamente na mídia, e que têm pouco espaço para a expressão da sua própria voz.

Das cinco publicações em língua portuguesa focalizadas no projeto integrado, quatro são street papers - três brasileiras: a Revista Ocas, de São Paulo, o jornal Boca de Rua, de Porto Alegre, o jornal Aurora da Rua, de Salvador; e uma portuguesa: a revista Cais, de Lisboa, objeto deste artigo. Essas publicações funcionam nos moldes da revista pioneira no gênero, a britânica The Big Issue, que circula em Londres desde 1991 e inspirou muitos dos jornais de rua hoje existentes. ${ }^{9}$

\footnotetext{
${ }^{9}$ Entre as publicações pesquisadas, apenas $O$ Trecheiro é um jornal de distribuição gratuita, que não se enquadra no conceito de street paper.
} 
Vinculadas à International Network of Street Papers (INSP - Rede Internacional de Jornais de Rua), há hoje mais de 100 dessas publicações, oriundas de mais de 40 países e de todos os continentes. Os quatro jornais de rua focalizados no projeto são todos pertencentes a essa rede, que atua "como uma plataforma global para vozes que nunca são ouvidas e defende os direitos das pessoas que vivem em situação de pobreza" (INSP, 2011). De acordo com a INSP, os street papers são definidos como jornais e revistas independentes, vocacionados a oferecer oportunidades de trabalho e geração de renda para pessoas em situação de rua, além de garantir um apoio social mais ampliado. Em relação à geração de renda, a distribuição dessas publicações acontece nas ruas, sendo vendidas por pessoas em situação de rua ou de risco. Cada vendedor/a administra a quantidade de jornais ou revistas que pretende comercializar, pagando pela unidade um valor que não ultrapassa a metade do preço de capa, e ficando com todo o dinheiro da venda. Em relação ao apoio social mais amplo, essas iniciativas costumam ser projetos de organizações não governamentais mais abrangentes, que sustentam tanto as publicações como outros projetos institucionais. É o caso dos quatro jornais de rua que são escopo do projeto integrado.

Vamos olhar para o caso específico da revista Cais, que é o recorte aqui. A Cais é sustentada pela Associação Cais, uma associação de solidariedade social que, criada em 1994, "tem como missão contribuir para o melhoramento global das condições de vida de pessoas sem casa/lar, social e economicamente vulneráveis, em situação de privação, exclusão e risco". A partir de 2003 houve uma expansão da área de atuação pela criação do Centro Cais, que apoia "pessoas sem casa e outros grupos excluídos e empobrecidos, na gestão de seu tempo livre". Hoje há dois desses centros em funcionamento, um em Lisboa e outro no Porto. Os objetivos declarados da associação são: "colocar na ordem do dia as temáticas relacionadas com a Pobreza e Exclusão social; potenciar o trabalho em Rede e consolidar parcerias; valorizar os beneficiários (utentes) do sistema social enquanto elementos críticos e activos; desenvolver e implementar estratégias de intervenção social adequadas às necessidades das populações alvo" (Cais, 2011).

Além da revista, a associação dirige outros projetos, e a revista Cais, um entre esses projetos, é definida como "um instrumento de capacitação para a participação de pessoas em situação de sem-abrigo". A revista, primeira criação da associação, tem o objetivo declarado de "despertar os leitores e a opinião pública em geral para as problemáticas sociais relacionadas com os sem-abrigo e com outras formas de exclusão”.

Iniciativas locais como essas - organizadas em uma rede global - anunciam um modelo diferente de mídia. Para além das mudanças estruturais 
das rotinas e práticas jornalísticas, estaria implicada aqui também uma mudança discursiva, em termos dos discursos ativados para a representação da situação de rua e para a identificação de pessoas em situação de rua nos street papers? Como vimos, discursos são modos relativamente estáveis de representação que se associam a diferentes perspectivas a respeito do mundo. Para além de seu aspecto representacional, pela dialética entre linguagem e sociedade entendemos que os diferentes discursos, materializados em textos concretos, têm efeitos sobre a sociedade, isto é, os sentidos de textos podem ter efeitos sobre a nossa compreensão de processos sociais e sobre os modos como reagimos a esses processos.

No caso dos jornais de rua, importa saber até que ponto as pessoas em situação de rua agem na definição das pautas jornalísticas e na composição dos textos e imagens veiculados; se há um sistema de compartilhamentos e trocas, nas etapas de produção, que possa superar o assistencialismo e favorecer uma participação cidadã efetiva, uma articulação de modos particulares de luta pela garantia de direitos. Nesse sentido, Walty (2007) reflete sobre o estabelecimento de parcerias entre intelectuais (jornalistas, estudantes, profissionais liberais, professores/as etc.) e pessoas em situação de rua na composição de textos, entendidos como enunciações compostas de distintas vozes, que se mesclam, construindo não só uma terceira voz, mas ampliando também o espaço público. E especulando sobre a natureza desse trabalho conjunto, a autora se pergunta como se relacionam intelectuais e pessoas em situação de rua no contexto dos jornais de rua: "Seriam os jornais de rua um exemplo da busca da palavra partilhada?" (Walty, 2007: 83-4).

A mídia alternativa, assim, poderia caracterizar uma oportunidade de democratização de acesso a tecnologias discursivas e a gêneros discursivos midiáticos, por exemplo, possibilitando, além disso, trocas de experiências entre grupos sociais apartados, o que favoreceria um reconhecimento mútuo, importante para a superação de preconceitos arraigados. No campo dos modos de representação, podem surgir daí hibridismos discursivos que possibilitem novas formas de compreensão da sociedade e dos problemas associados à má distribuição de recursos e de oportunidades.

É para compreender essas práticas, o seu funcionamento em sua relação com outras práticas sociais e conjunturas mais amplas, que o trabalho de campo é necessário ao projeto integrado. Considerando que a compreensão dessa rede de práticas não poderia resultar da análise isolada dos textos publicados, concentro-me, na próxima seção, na reflexão sobre o trabalho de campo realizado em Lisboa. 


\section{O trabalho de campo em Lisboa: geração e coleta de dados}

$\mathrm{Na}$ etapa da pesquisa realizada em Portugal, visitei o Centro Cais de Lisboa em 1. ${ }^{\circ}$ de julho de 2010. Antes da entrevista, o editor mostrou-me as amplas instalações da Associação Cais - Círculo de Apoio à Integração dos Sem-Abrigo. ${ }^{10} \mathrm{Na}$ parte de cima, ficam os serviços administrativos e de edição; na parte de baixo, há uma sala de convivência, com televisão, sofás, computadores; um restaurante social que serve almoços a 1,50€; um banco de alimentos e um depósito de roupas para doação; o arquivo histórico da revista. Há, ainda, uma ampla área externa. Havia um fluxo de pessoas que utilizavam o espaço, além de profissionais, em sua maioria mulheres, que prestam serviço para a Cais no atendimento aos/às "utentes" do Centro. ${ }^{11}$

Sentamos ao restaurante para a entrevista. Foi gravada uma entrevista focalizada com o editor da revista Cais. ${ }^{12}$ Esse tipo de entrevista permite que a interação se desenvolva mais livremente, ainda que focalizada em pontos específicos de interesse (Doncaster, 1998). Para uma entrevista focalizada, não é desejável uma lista de perguntas a serem feitas, mas é útil levantar desde o início os temas a serem abordados, elaborando-se um tópico-guia (Gaskell, 2005). O tópico-guia para a entrevista foi elaborado com os seguintes eixos temáticos:

\begin{tabular}{|l|}
\hline \multicolumn{1}{|c|}{ Tópico-guia para as entrevistas focalizadas com editores/as: eixos temáticos } \\
\hline 1. Constituição da publicação (história/sucessos/dificuldades/parcerias/equipe) \\
\hline $\begin{array}{l}\text { 2. Organização e interação do grupo de ação: equipe de produção e pessoas em situação } \\
\text { de rua }\end{array}$ \\
\hline $\begin{array}{l}\text { 3. A experiência com o trabalho na publicação (benefícios/responsabilidades/dificuldades/ } \\
\text { sucessos) }\end{array}$ \\
\hline $\begin{array}{l}\text { 4. A produção/edição/publicação de textos (participação ou não de pessoas em situação } \\
\text { de rua) }\end{array}$ \\
\hline 5. Efeitos sobre políticas públicas (ou não) \\
\hline
\end{tabular}

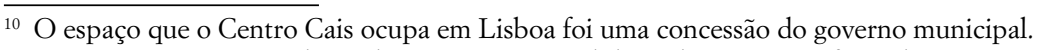

11 "Utentes" é como são chamadas as pessoas atendidas pelos serviços oferecidos no Centro. De acordo com o editor, na entrevista que me concedeu, "são pessoas que estão institucionalizadas; muitas delas vivendo nas ruas sem-abrigo foram recolhidas por instituições. As pessoas vão lá, podem dormir e podem jantar só, mas durante o dia têm que ir pra rua. Pra não tarem na rua, alguns deles vêm pra Cais, passam aqui o dia, almoçam aqui, pagam um euro e meio para almoçar, vão aí para os computadores, têm aulas de formação em inglês, português para estrangeiros, futebol, agora tem de tecnologias, TICs, têm formação, e aqui estão ocupados o dia inteiro".

12 O diretor da publicação havia sido contactado por correio eletrônico já em abril de 2010, quando afirmou interesse e concordou em colaborar na pesquisa. Com o editor que entrevistei travei contato em maio de 2011. 
O trecho da entrevista selecionado para análise neste artigo orienta-se pelo eixo temático 4 , de modo que a entrevista será explorada tendo em vista a participação ou não de pessoas em situação de rua na produção de textos, de acordo com as representações desse tema por parte do editor.

No que diz respeito à história da constituição da Cais, o editor contou-me que a revista passou por três fases diferentes desde a sua fundação no final de 1994. No início, a Cais tinha menos conteúdo textual e mais imagens - baseava-se no conceito de fotojornalismo. Desde essa fase inicial, era uma revista que visava ser de interesse para o público em geral, e não uma revista especificamente sobre a situação de rua. A partir de 2001, tornou-se uma revista temática, mas voltada para temas da atualidade: cada edição explorava um tema específico, e eram convidadas várias pessoas a colaborar com textos e fotografias. Mais tarde, o objetivo passou a ser "fazer uma revista mais de acordo com o modelo da imprensa comercial; uma revista que tem várias secções. [...] Esse é um formato de uma revista mais aberta, mais para o grande público, mais jornalística" (entrevista com o editor).

As seções temáticas são fixas - aparecem em todos os números e são assinadas sempre pelas mesmas pessoas, especialistas que doam os seus textos para a associação, tornando-se assim colaboradores/as da Cais. Grande parte deles/as são pessoas ligadas ao mundo acadêmico; muitos/as são professores/as de instituições universitárias. As seções orbitam em torno de temas como meio ambiente, tecnologia, empreendedorismo, justiça, sociedade, política, esporte. Entre outras seções fixas, publica-se também a "página do vendedor", que traça o perfil de um/a vendedor/a da Cais a cada edição - essa seção é o foco do trecho da entrevista selecionado para análise.

As iniciativas da associação, assim como a revista, são sustentadas por convênios firmados com uma série de patrocinadores, incluindo o Estado. Quando perguntei se a Associação e a revista têm ou tiveram alguma influência sobre a formulação de políticas públicas, o editor me respondeu assim:

Eh... não me parece. Não me parece. O que pode ter... ou seja, a Associação é reconhecida pela tutela da área social do Estado, do governo, do ministério, há um reconhecimento ao longo dos anos, crescente, do trabalho não só da Cais mas de várias IPSS, que são as várias Instituições Particulares de Solidariedade Social, que há imensas em Portugal, umas 500. Há muita gente a trabalhar. Os governos passam, a Cais tem crescido. A Cais tem sido muito reconhecida como uma instituição de mérito, e até de utilidade pública, portanto tem esse estatuto. Pronto. Mas isso é diferente da associação Cais em si conseguir... Talvez possa criar um certo pressing... Quem pode criar esse pressing de influência junto do governo é a chamada Confederação Nacional das IPSS. Ou seja, são 500, há uma confederação, então dá outra 
força. A Cais é uma, mais 499, isso pode ser uma pressão. Há uma confederação, e essa confederação tem reuniões com ministérios de trabalho, de seguridade social, e apresenta soluções, apresenta ideias; é um parceiro, pode fazer força de influência. Aí sim. (Entrevista com o editor)

O que se nota, portanto, é que a Associação Cais, como Instituição Particular de Solidariedade Social, atua de fato na lacuna deixada pela demissão do Estado, oferecendo serviços de capacitação (cursos de línguas e de uso de tecnologias, por exemplo), organizando a doação de alimentos e roupas, servindo de espaço de convívio e oferecendo a possibilidade de geração de renda que a venda da revista representa. Não se trata, entretanto, de um movimento de papel reivindicatório que atue como pressão sobre o Estado.

Também no dia $1 .^{\circ}$ de julho, foram coletadas as cinco últimas edições da revista Cais. Esses textos compõem outro corpus analítico da pesquisa. As análises de textos publicados na Cais possibilitarão a investigação da representação da situação de rua e dos direitos de cidadania, e a investigação da construção de modos de identificação de pessoas em situação de rua, nos volumes da publicação em que o tema é tratado - já que a situação de rua não é um tema pautado em todas as edições da Cais. Sobre isso, o editor me disse:

a revista não aborda as chamadas questões mais dolorosas da vida do público que beneficia, os sem-abrigo, a pobreza. A Cais não vai ali ao fundo, mostrar as misérias, a Cais tem que mostrar o lado bom das coisas. O público não quer estar a ler misérias, tragédias, o próprio público já não... E portanto a base é tentar fazer uma revista que interesse às pessoas comprar. (Entrevista com o editor)

Essa informação contradiz o objetivo declarado da Cais, o de "despertar os leitores e a opinião pública em geral para as problemáticas sociais relacionadas com os sem-abrigo e com outras formas de exclusão" (Cais, 2011). Trazer essa temática para a agenda de debate da sociedade poderia ser uma forma de travar um combate explícito contra a invisibilidade da questão social, um compromisso assumido também pela INSP. A relevância desse compromisso é ressaltada em Pardo:

Sabemos que a ignorância continua sendo uma das melhores ferramentas para se exercerem o abuso e a submissão. Por essa razão, cremos que trazer à luz o que as pessoas que vivem em situação de pobreza extrema sentem e pensam sobre suas próprias necessidades [...] é, ao mesmo tempo, uma forma de começar a trilhar o caminho da justiça social. (2008: 26) 
Os dados obtidos nesse trabalho de campo voltarão a ser focalizados em etapa posterior da investigação. Neste artigo, será explorado apenas um recorte da transcrição da entrevista com o editor. Do texto resultante da transcrição da entrevista, focalizo aqui a parte em que se trata da participação de pessoas em situação de rua na produção de textos para a revista. Meu interesse específico é mapear os modos de representação discursiva das pessoas em situação de rua classificadas como "vendedores/as" na entrevista.

\section{A entrevista com o editor: quem são e o que fazem os/as vendedores/as?}

Nesta seção, veremos como a participação (ou não) de pessoas em situação de rua na produção da revista é representada na entrevista realizada, em Lisboa, com o editor da Cais. Da transcrição da entrevista, dados os limites do gênero 'artigo acadêmico', foi selecionado apenas um excerto, que trata especificamente da posição que vendedores/as da Cais ocupam na dinâmica da revista. O trecho aborda a "página do vendedor", uma seção que, como já foi referido, é recorrente em todos os volumes de Cais e representa um/a vendedor/a da revista. Essa representação é feita por meio de uma fotografia colorida, em plano fechado, abaixo da qual se lê "Revista Cais", em letras maiúsculas, e uma linha abaixo "Um instrumento de capacitação para a participação de pessoas em situação de sem-abrigo". Ao lado da imagem, aparece uma representação de fala dessa pessoa retratada, contando sobre a sua experiência como vendedor/a da Cais. O texto aparece entre aspas e em primeira pessoa, dando a entender que se trata de um texto próprio ou de uma transcrição da sua fala. ${ }^{13}$ Entretanto, na entrevista com o editor, quando falamos sobre essa seção ele me contou:

Editor - Esta é a página do vendedor. Então temos vários vendedores, e para dar um certo protagonismo ao vendedor, para o público que comprar a revista também olhar melhor para o vendedor, não é só na rua, ele está aqui também. Para dar mais, mais... dignificar também o vendedor, a figura do vendedor.

Viviane - E aí ele escreve um pequeno texto [ ]

Editor - [ ] Não, isso sou eu é que escrevo. Ou seja, isto é... eu pergunto à pessoa 'Ó, meu amigo, para si, o que sente quando vende a revista Cais na rua?' Ele me fala 'Ah, eu gosto muito, falo com as pessoas, ganho algum dinheiro, pra mim tá bom'. Eu escrevo isso. Tás a ver? ${ }^{14}$

\footnotetext{
${ }^{13}$ Embora o conteúdo da revista Cais não esteja disponível na Internet, no sítio da Associação Cais há uma seção que se assemelha à "Página do Vendedor". Trata-se da seção "Testemunhos", disponível em http://www.cais.pt/testemunhos.

${ }^{14} \mathrm{Na}$ transcrição, as interpolações foram identificadas por meio de parênteses retos [ ], e as ideias deixadas incompletas no texto falado e gravado estão sinalizadas com reticências.
} 
Para começar a análise desse excerto, vamos procurar identificar como o elemento "vendedor" aparece representado na estrutura das orações. Para isso, recorreremos, ainda que de modo um tanto solto, ao Sistema de Transitividade desenvolvido na Linguística Sistêmico-Funcional (LSF). Não interessa, aqui, esmiuçar os detalhes do complexo Sistema de Transitividade tal como proposto por Halliday (2004), e por isso vou me abster de entrar em detalhes sobre os processos e os participantes oracionais associados. Apenas utilizarei o referencial como ferramenta para verificar o grau de agentividade atribuído ao participante "vendedor" na representação do editor, sem, contudo, utilizar as nomenclaturas próprias do jargão específico dessa teoria linguística, exceto quando necessário. Em termos da recontextualização desse referencial na ADC, o Sistema de Transitividade, associando diferentes papéis de participantes (grupos nominais) a diferentes processos $^{15}$ (grupos verbais) em diferentes circunstâncias (grupos adverbiais), relaciona-se ao significado representacional do discurso, ou seja, aos modos como representamos aspectos do mundo e como, nessa tarefa, mobilizamos discursos, entendidos como modos relativamente estáveis de representação.

Então vejamos: o excerto gira em torno da seção "página do vendedor", e é esse o assunto que dá início ao trecho do diálogo. O editor mostra "Esta é a página no vendedor”, e de fato estávamos diante de uma edição da revista aberta nessa seção. Tudo o que segue nessa primeira fala do editor no excerto é qualificação, descrição, circunstancialização da seção. De fato, há muitas estruturas preposicionais nesse trecho, com valor de circunstância de finalidade, de propósito: "para dar um certo protagonismo ao vendedor", "para o público [...] olhar melhor para o vendedor", "para dar mais, mais... dignificar o vendedor, a figura do vendedor". O que o editor realiza discursivamente nesse trecho da entrevista, então, é uma justificação circunstanciada da seção em foco.

Se olharmos para o espaço que "vendedor(es)" assume na representação de propósito presente na primeira fala do editor no excerto, teremos o seguinte mapeamento:

\footnotetext{
15 "De acordo com Halliday (2004, p. 172), os processos principais são os materiais, pelos quais se representam ações, eventos; os mentais, que representam percepções, emoções; e os relacionais, que identificam, caracterizam participantes. Os secundários, que se encontram nas fronteiras entre os principais, são os comportamentais, que representam comportamentos humanos; os verbais, que representam ações de dizer, pronunciamentos, e, por fim, os existenciais, que representam o que existe." (Ramalho e Resende, 2011: 139-40, grifos no original).
} 
QUADRO 1 - Mapeamento do elemento “vendedor(es)" na representação

\begin{tabular}{|l|l|}
\hline Emissão & Lugar de 'vendedor(es)' na emissão \\
\hline (i) Esta é a página do vendedor. & Pós-modificador/ qualificador de “página" \\
\hline (ii) Então temos vários vendedores, e & Atributo de 'ter' (é a Cais que tem) \\
\hline $\begin{array}{l}\text { (iii) para dar um certo protagonismo ao } \\
\text { vendedor, }\end{array}$ & Beneficiário da ação de Cais (é a Cais que dá) \\
\hline $\begin{array}{l}\text { (iv) para o público que comprar a revista } \\
\text { também olhar melhor para o vendedor, }\end{array}$ & $\begin{array}{l}\text { Objeto do olhar, da apreciação do público } \\
\text { consumidor de Cais (é o público que olha) }\end{array}$ \\
\hline (v) não é só na rua, ele está aqui também. & $\begin{array}{l}\text { Representação por pronome em processo } \\
\text { relacional circunstancial (estar em) }\end{array}$ \\
\hline $\begin{array}{l}\text { (vi) Para dar mais, mais... dignificar também } \\
\text { o vendedor, a figura do vendedor. }\end{array}$ & $\begin{array}{l}\text { Beneficiário da ação de Cais (é a Cais que } \\
\text { dignifica) }\end{array}$ \\
\hline
\end{tabular}

Em todos os casos, o elemento 'vendedor(es)' tem agência ofuscada, sendo representado como entidade sobretudo passiva - não se representa, em nenhuma dessas instâncias, uma ação no mundo por parte desse grupo. A representação de vendedores/as de Cais pelo editor se dá principalmente como beneficiários/as da ação de Cais ('dar protagonismo' e 'dignificar', em (iii) e (vi)). Note-se que, na instância "para dar um certo protagonismo ao vendedor", mesmo esse protagonismo (do qual o "vendedor" é objeto passivo) é texturizado com uma modalidade de baixa afinidade - isto é, a pré-modificação de "protagonismo" por "um certo" enfraquece o protagonismo na representação, diluindo o comprometimento do enunciador com aquilo que enuncia. ${ }^{16}$

O grupo 'vendedor(es)' também é representado como objeto do olhar e da apreciação do público consumidor da revista, em (iv). Nesse caso, pela texturização com 'melhor' em "olhar melhor", ativa-se o pressuposto de que o grupo não é bem visto - isso está pressuposto porque não é posto claramente, mas pode ser depreendido da superfície textual. ${ }^{17}$ Outra estrutura

\footnotetext{
${ }^{16}$ Segundo Halliday (2004: 75), a modalidade é "o julgamento do falante sobre as probabilidades ou obrigatoriedades envolvidas no que diz". Para Fairclough (2003: 166), "a questão da modalidade pode ser vista como a questão de quanto as pessoas se comprometem quando fazem afirmações, perguntas, demandas ou ofertas". Afirmações e perguntas referem-se à troca de conhecimento; demandas e ofertas referem-se à troca de atividade. Em trocas de conhecimento, a modalidade é epistêmica, refere-se ao comprometimento com a 'verdade'; em trocas de atividade, a modalidade é deôntica, refere-se ao comprometimento com a obrigatoriedade/necessidade. No exemplo estudado, temos uma modalidade epistêmica de baixa afinidade.

${ }^{17}$ Fairclough (2001: 155) define pressuposições como "proposições tomadas pelo produtor do texto como já estabelecidas ou 'dadas'”, que podem ser engatilhadas por diversos recursos linguísticos.
} 
de pressuposição aparece pela seleção lexical de "dignificar”, já que, pela sufixação com '-ficar', 'dignificar' significa 'tornar digno'. Assim, a identificação de pessoas em situação de rua nessa fala, notadamente do grupo identificado como 'vendedor(es)' da revista Cais, é negativa - as pessoas são identificadas como passivas, pelas escolhas dos processos que as representam e da sua localização nas estruturas oracionais, além de serem identificadas como mal vistas e carentes de dignificação.

Não aparecem no trecho - e em todo o texto da entrevista - representações do grupo como capaz de agir para operar mudanças nesse estado de coisas. Há uma única instância em que 'o vendedor' da Cais assume posição ativa na estrutura oracional - isso acontece na emissão (v), "ele está aqui também" -, mas como portador em processo relacional circunstancial, do tipo 'estar em', o que representa uma condição, mais que uma ação.

$\mathrm{Na}$ sequência, aparece na transcrição uma intervenção minha, quando, orientada pelas aspas que sinalizam as falas de vendedores/as apresentadas na seção da "página do vendedor", imagino que os textos fossem escritos por vendedores/as: "E aí eles escrevem um pequeno texto [ ]". O editor logo me corrige, informando que é ele quem escreve os pequenos textos apresentados entre aspas junto às fotografias dos/as vendedores/as representados/as nessa página. ${ }^{18}$ Em sua explicação, hesita - "Ou seja, isto é..." - e depois conta que pergunta à pessoa como se sente como vendedora da Cais, e texturiza a informação no texto que será publicado. Por mais bem-intencionada que seja a formulação dessa página - e jamais duvidei da excelente intenção das pessoas que se dedicam a essa iniciativa, nem é meu objetivo aqui julgar isso -, precisamos reconhecer que estamos diante de uma relação de poder que limita o que o/a vendedor/a pode dizer ao editor quando perguntado sobre "o que sente quando vende a revista Cais na rua". E essa voz, já constrangida pelos limites da relação de poder, é retexturizada pela voz institucional que, por sua vez, tem interesse em formular uma representação positiva da venda de Cais, e reenquadra essa voz num esquema já fixado: "eu gosto muito, falo com as pessoas, ganho algum dinheiro, pra mim tá bom”.

Isso pode justificar a relexicalização presente na última frase da primeira fala do editor no recorte: "dignificar o vendedor, a figura do vendedor". Nessa representação do grupo, "o vendedor" é relexicalizado como "a figura do vendedor”. Não se trata da autorrepresentação ou mesmo da representação de um/a vendedor/a específico/a na página, mas da criação discursiva

${ }^{18}$ Já ao final da entrevista, quando perguntei especificamente sobre a participação de pessoas em situação de rua na produção da revista, o editor confirmou a ausência de participação efetiva de vendedores/as na produção dessa seção: "a página do vendedor a pessoa não participa, só se deixa fotografar e dá uma opinião sobre o que ela acha de vender”. 
de um grupo com características mais ou menos homogêneas. Conforma-se assim o que se pode chamar de "a figura do vendedor".

Assim, no que tange à representação do grupo 'vendedores' na entrevista, assume-se uma condição de passividade ou de imobilidade. Discursivamente, isso se constrói pela carência de processos de fazer e pela negação da participação nos processos de produção da revista.

\section{Considerações finais}

A representação de 'vendedor(es)' nos excertos tende para uma condição de passividade, o que se confirma na análise dos processos associados a esse elemento nas estruturas oracionais, pela carência de processos de fazer, que poderiam representar a sua ação material no mundo. Não há uma representação do grupo como capaz de atuar, de assumir posição ativa na transformação da sua situação ou mesmo de participar nas tomadas de decisão relativas a ações nessa direção.

Embora isso não seja texturizado explicitamente na superfície do texto, a análise das estruturas oracionais e das pressuposições foi capaz de mostrar que pessoas em situação de rua são representadas no texto como passivas, aparecendo posicionadas em um lugar passivo em termos de ações para a mudança social. Essa representação do grupo de pessoas em situação de rua classificado como 'vendedores' adquire relevo se concordamos com Spivak que "a possibilidade de existência da própria coletividade é [ou pode ser] persistentemente negada pela manipulação do agenciamento” (2010: 55; acréscimo meu). De acordo com os dados analisados, na representação das práticas de produção da revista pelo editor, a venda da Cais assume valor instrumental, de fonte de geração de renda, mas não se associa, na representação, valor simbólico a essa ação. A ausência de participação desse grupo nos processos de produção da revista mantém as suas vozes silenciadas - não opinam na definição de pautas nem se autorrepresentam em textos publicados.

Em termos dos discursos mobilizados pela Associação Cais para a orientação da sua prática, podemos dizer que o discurso do assistencialismo é forte, e que o discurso do protagonismo, embora enunciado na definição da revista como "um instrumento de capacitação para a participação de pessoas em situação de sem-abrigo", não resiste à tendência da assistência (Cais, 2011; grifos meus). Para Resende (2008: 287), isso se associa a uma mudança discursiva mais ampla, de que a situação nessa Associação pode ser um efeito:

a celebração da participação da sociedade civil na esfera pública garantia o interesse em projetos de mobilização, [mas] na conjuntura atual a participação da sociedade parece mais voltada para suprir a carência dos serviços abandonados pelo Estado, em 
programas nos quais a sociedade é convidada a participar em termos de voluntariado. $\mathrm{O}$ discurso da mobilização parece ter-se enfraquecido no embate com o discurso da assistência - enquanto o discurso da mobilização social prega o protagonismo da sociedade na resolução de problemas sociais (como a pobreza, por exemplo), o discurso da assistência reconhece os problemas sociais mas privilegia soluções que não emanam das próprias populações que sofrem com os problemas identificados, mas da assistência/caridade de outros setores da sociedade.

Se considerarmos que as pessoas envolvidas nas práticas da Associação e da revista são pessoas engajadas na causa do combate à pobreza extrema, podemos perguntar-nos por que assimilam discursos que têm como efeito uma redução das suas 'condições de possibilidade'. Nesse sentido, ressalta-se o papel do elemento discursivo, já que a circulação massiva de discursos poderosos, como o discurso assistencialista, o discurso da imobilidade das estruturas ou o discurso da incapacidade de organização para o protagonismo, tem como efeito uma desarticulação de forças engajadas em alternativas e o enfraquecimento do debate público.

Não pretendo aqui fazer uma crítica desconstrutiva do esforço empreendido nessa iniciativa. Sabemos que a saída das ruas é um processo difícil, e que apoios como o oferecido pela Associação Cais podem ser fundamentais para o indivíduo que enfrenta esse processo. A revista Cais como instrumento de geração de renda parece ser bem-sucedida, e esse esforço não deve ser minimizado. Entretanto, uma iniciativa com a envergadura da Associação Cais, e com um suporte midiático da qualidade da revista Cais poderia representar um espaço simbólico efetivo para a autorrepresentação e a auto-organização. E isso poderia significar muito mais, favorecendo a expressão de vozes no mais das vezes silenciadas pela mídia e a formação de um ator social coletivo capaz de mobilização pela mudança social. Nos termos do Realismo Crítico, uma revisão dessa natureza nas práticas de produção da revista poderia favorecer a emergência não só de novos discursos, híbridos em sua origem, como também de novas condições de possibilidade, em que o protagonismo pudesse 'sair do papel'.

Há que reconhecer a existência de um esforço no sentido da incorporação de papel protagonista, se não por vendedores/as da revista especificamente, ao menos por "utentes" da Associação Cais. Esse esforço pode ser observado na dinâmica de organização da seção Repórteres de Rua. As páginas aí publicadas são efetivamente uma produção colaborativa, resultado de oficinas em que os/as participantes são estimulados/as a colaborar com sugestões para definição de pauta e com produtos textuais e imagéticos de autoria coletiva. Participei de uma dessas oficinas, também em minha visita de julho 
de 2011, e considero o projeto de grande relevância para a construção de relações de um tipo novo na dinâmica da revista Cais. $\mathrm{Na}$ ocasião, tive a oportunidade de gravar uma inspiradora entrevista com a coordenadora do projeto Repórteres de Rua, e esse material ainda será analisado com as ferramentas da ADC, sendo objeto para artigo futuro.

No que se refere ao projeto integrado de que este artigo é recorte, neste momento há um grupo de pesquisadores/as trabalhando na investigação das publicações brasileiras - o jornal O Trecheiro e a revista Ocas, de São Paulo, e os jornais Aurora da Rua, de Salvador, e Boca de Rua, de Porto Alegre. Os trabalhos de campo em São Paulo e Porto Alegre ainda serão realizados em 2012, mas a visita à sede do Aurora da Rua em Salvador já foi levada a cabo, com a gravação de entrevistas com duas jornalistas, o editor, vendedores/as e ex-vendedores/as do jornal. ${ }^{19}$ Embora os dados ainda estejam em análise, já sabemos que na produção baiana há participação mais efetiva de pessoas em situação de rua, que decidem colaborativamente a pauta de cada edição e o tema da matéria de capa.

A comparação entre o Aurora da Rua e a Cais é difícil por dois motivos. Em primeiro lugar, trata-se de mídias muito distintas e com diferentes objetivos - o jornal Aurora da Rua é também uma produção de qualidade, com excelente diagramação, inclusive premiada, mas é um jornal e não uma revista, e tem foco muito mais específico na situação de rua do que a revista Cais (nesse sentido, uma comparação mais adequada poderia ser feita com a dinâmica da revista Ocas, mas ainda não temos os dados de campo de São Paulo). A comparação entre o Aurora e a Cais é complexa ainda por um segundo motivo: no Brasil, está se fortalecendo a cada dia um movimento social muito atuante na questão da situação de rua - o Movimento Nacional da População de Rua (MNPR), e Salvador é um dos principais redutos desse Movimento, ao lado de São Paulo, Brasília e Belo Horizonte. Uma das coordenadoras mais atuantes do MNPR é ex-vendedora do Aurora da Rua e permanece vinculada ao projeto, ainda que já não seja uma colaboradora direta. Acredito que essa movimentação no contexto brasileiro seja um catalisador do protagonismo também nos street papers aí gestados, mas por ora isso não é mais que uma questão aberta, ainda a ser investigada.

${ }_{19}$ Esse trabalho de campo foi realizado pelo pesquisador Gersiney Pablo dos Santos em fevereiro de 2012, com apoio do Decanato de Pós-Graduação da Universidade de Brasília (DPP/UnB), Edital 6/2011. 


\section{Referências bibliográficas}

Bhaskar, Roy (1989), The Possibility of Naturalism. A Philosophical Critique of the Contemporary Human Sciences. Hemel Hempstead: Harvester Wheatsheaf, 1989. Bhaskar, Roy (1998), "Philosophy and scientific realism", in Margareth Archer et al. (orgs.), Critical Realism. Essential Readings. London, New York: Routledge, 16-47.

Bakhtin, Mikail, Estética da criação verbal. São Paulo: Martins Fontes, 1992.

Blommaert, Jan (2005), Discourse. A Critical Introduction. Cambridge: Cambridge University Press.

Bourdieu, Pierre (1998), Contrafogos. Trad. L. Magalhães. Rio de Janeiro: Jorge Zahar.

Buarque, Cristovam (2001), Admirável mundo atual. Dicionário pessoal dos horrores e esperanças do mundo globalizado. São Paulo: Geração Editorial.

Cais (2011), "Um instrumento de capacitação para a participação de pessoas em situação de sem-abrigo". Consultado a 15.07.2011, em http://www.cais.pt/projectos/view/5/ revista-cais.

Chouliaraki, Lilie; Fairclough, Norman (1999), Discourse in Late Modernity. Rethinking Critical Discourse Analysis. Edinburgh: Edinburgh University Press.

Cunha, Maria Angélica Furtado; Souza, Maria Medianeira (2007), Transitividade e seus contextos de uso. Rio de Janeiro: Lucerna.

Doncaster, Kathy (1998), "Some reflections on relations of power between researcher and researched in a set of interviews", in Simon Gieve e Izabel Magalhães (orgs.), Proceedings of the $4^{\text {th }}$ Annual C.R.I.L.E. Seminar. Lancaster University, 71-79.

Fairclough, Norman (2001), Discurso e mudança social. Brasília: Universidade de Brasília.

Fairclough, Norman (2003), Analysing Discourse. Textual Analysis for Social Research. London: Routledge.

Gaskell, George (2005), "Entrevistas individuais e grupais", in Martin W. Bauer e George Gaskell (orgs.), Pesquisa Qualitativa com Texto, Imagem e Som. Trad. P. A. Guareschi. Petrópolis: Vozes, 64-89.

Halliday, Michael (2004), An Introduction to Functional Grammar. Revisão Christian Matthiessen. London: Hodder Arnold.

Harvey, David (1992), Condição pós-moderna: uma pesquisa sobre as origens da mudança cultural. São Paulo: Loyola.

INSP - International Network of Street Papers (2011), "What is a street paper?”. Consultado a 15.07.2011, em http://www.street-papers.org.

Magalhães, Izabel (2000), Eu e tu. A constituição do sujeito no discurso médico. Brasília: Thesaurus.

Magalhães, Izabel (2005), "Introdução: a Análise de Discurso Crítica", DELTA, 21 (especial), 1-11.

Meurer, José Luiz (2004), "Ampliando a noção de contexto na linguística sistêmico-funcional e na análise crítica do discurso”, Linguagem em (Dis)curso, 4, 133- 157. 
Montecino, Lésmer (org.) (2010), Discurso, pobreza y exclusión en América Latina. Santiago do Chile: Editorial Cuarto Propio.

Pardo, María Laura (org.) (2008), El discurso sobre la pobreza en América Latina. Santiago do Chile: Frasis.

Pardo Abril, Neyla (2007), Como hacer Análisis Crítico del Discurso. Santiago: Frasis.

Pardo Abril, Neyla (2008), ¿Que nos dicen? ¿Que vemos? ¿Que és... pobreza? Bogotá: Universidad Nacional de Colômbia.

Quiroz, Beatriz (2008), "La identidad vinculada a la calle en el discurso de personas sin techo”, in María Laura Pardo (org.), El discurso sobre la pobreza en América Latina. Santiago: Frasis, 79-97.

Ramalho, Viviane (2010), Análise de discurso crítica da publicidade. Um estudo sobre a promoção de medicamentos no Brasil. Portugal/Covilhã: Labcom.

Ramalho, Viviane; Resende, Viviane de Melo (2011), Análise de discurso (para a) crítica. O texto como material de pesquisa. Campinas: Pontes.

Resende, Viviane de Melo (2008), “Análise de Discurso Crítica e etnografia: o Movimento Nacional de Meninos e Meninas de Rua, sua crise e o protagonismo juvenil”. Tese de Doutorado. Universidade de Brasília. Programa de Pós-Graduação em Linguística.

Resende, Viviane de Melo (2009), Análise de Discurso Crítica e Realismo Crítico. Implicações interdisciplinares. Campinas: Pontes.

Resende, Viviane de Melo (2010), "Between the European Legacy and Critical Daring: Epistemological Reflections for Critical Discourse Analyses”, Journal of Multicultural Discourses, 5(3), 193-212.

Richardson, John E. (2007), Analysing Newspapers. An Approach from Critical Discourse Analysis. Hampshire. New York: Palgrave Macmillan.

Santos, Milton (2000), Por uma outra globalização. Do pensamento único à consciência universal. São Paulo: Record.

Spivak, Gayatri C. (2010), Pode o subalterno falar? Belo Horizonte: UFMG.

Thompson, John B. (1995), Ideologia e cultura moderna. Petrópolis: Vozes.

van Dijk, Teun (2008), Discurso e poder. São Paulo: Contexto.

Walty, Ivete (2007), "Os intelectuais e os moradores de rua: uma parceria em construção?”, Letras de Hoje, 42(4), 77-84.

Wodak, Ruth (2003), "De qué trata el análisis crítico del discurso (ACD). Resumen de su historia, sus conceptos fundamentales y sus desarrollos", in Ruth Wodak e Michael Meyer (orgs.), Métodos de Análisis Crítico del Discurso. Barcelona: Gedisa, 17-34. 